Scip/. $0_{\text {Braeil }}$ toc previous next author subject form home alpha

Revista Brasileira de Geofísica Print version ISSN 0102-261X

Rev. Bras. Geof. vol.15 no.3 São Paulo Nov. 1997

http://dx.doi.org/10.1590/S0102-261X1997000300001

\section{Migração em duas etapas de dados ordenados em afastamento comum}

\author{
R. da Cruz Pestana ${ }^{1}$ \& M. S. Costa 2 \\ ${ }^{1}$ Departamento de Geofísica Nuclear, Instituto de Física/CPGG \\ Universidade Federal da Bahia \\ Rua Barão de Geremoabo, 128 - Campus Universitário da Ondina \\ Salvador - BA - CEP 40210-350 \\ E-mail: reynam@pppg.ufba.br \\ 2 Petrobras/GEXP/GETAB/SAG \\ Av. Antonio Carlos Magalhães - Salvador - BA - CEP 40000-000 \\ E-mail: msergio@ep-ba.petrobras.com.br
}

My SCIELO

Custom services

Services on Demand

Article

Article in xml format

Article references

How to cite this article

Curriculum ScienTI

Automatic translation

Send this article by e-mail

Indicators

Related links

Bookmark

I More

Este trabalho apresenta um método de migração antes do empilhamento de dados sísmicos ordenados em afastamento comum e ponto médio para meios com variação vertical e lateral de velocidade. A continuação descendente do campo de onda $P(t, y, h, z=0)$, transformado para o domínio $\left(w, k_{y}, k_{h}\right)$, é realizada através da equação de migraçao de raiz quadrada dupla, e a integral dos números de onda de afastamento $\left(k_{h}\right)$ é computada através do método de fase estacionária. A extrapolação de cada seção de afastamento constante é realizada de forma recursiva e em duas etapas. Na primeira etapa, o campo de onda é continuado para baixo, no domínio w - $k_{y}$, usando-se uma velocidade média equivalente até o nível de profundidade desejado, e em seguida uma correção do tipo "split-step" é aplicada nos dados convertidos para o domínio w - $y$, visando compensar as variações laterais existentes no campo de velocidade. O método foi testado em dados sintéticos gerados a partir de modelos com variação lateral e vertical de velocidade. A migração em duas etapas de dados ordenados em afastamento comum é computacionalmente eficiente e os resultados obtidos demonstram que o método funciona corretamente em meios com variação vertical de velocidade, contudo, a sua eficácia é limitada em dados com grandes afastamentos e fortes variações laterais de velocidade.

Palavras-chaves: Migração antes do empilhamento; Ondas planas; Afastamento comum.

Split-step migration of constant offset data - This work describes a new method of pre-stack migration of seismic data in common offset domain on media with lateral and vertical velocity variation. To perform the downward continuation of the wavefield $\mathrm{P}(\mathrm{t}, \mathrm{y}, \mathrm{h}, \mathrm{z}=0)$ transformed to domain $\left(\mathrm{w}, \mathrm{k}_{\mathrm{y}}, \mathrm{k}_{\mathrm{h}}\right)$ we use the double square root prestack migration equation with the integration along $k_{h}$ axis computed by the stationary phase method. The extrapolation of the wave field is realized in two steps. In the first, the wave field is downward continued in depth in the ( $\mathrm{w}, \mathrm{k}_{\mathrm{y}}$ ) domain, using a reference velocity. Afterwards we apply a second correction in the $(\mathrm{w}, \mathrm{y})$ domain, like in the split-step migration method - a correction that attempts to compensate for lateral velocity variations. The split-step migration of constant offset data is very fast and, according to our results, this method offers good results on synthetic data with vertical velocity variation. However, it shows limited efficiency on data with large offset and strong lateral variations.

Key words: Pre-stack migration; Plane waves; Constant offset. 


\section{INTRODUÇÃO}

O processo de migração em profundidade de dados sísmicos visa obter uma imagem da subsuperfície a partir dos dados registrados na superfície da Terra. Ele converte os padrões de reflexões em tempo na verdadeira posição espacial dos refletores; além de focalizar as difrações e melhorar a relação sinal ruído da seção migrada A extrapolação do campo de onda em subsuperfície e a construção de imagem são as duas etapas básicas deste processo. Estas etapas só serão bem realizadas quando se dispõe de uma boa estimativa do campo de velocidade de subsuperfície.

O processo convencional de migração inclui a geração de uma seção de ponto comum ou CMP ("CommonMid-point"), correção de sobretempo normal, mais conhecida por correção NMO, e o empilhamento, gerando uma seção de afastamento nulo para a migração em seguida. Contudo, o processamento de dados sísmicos no domínio CMP é muitas das vezes inadequado, principalmente em áreas geologicamente complexas. Nesses casos, as migrações em tempo ou em profundidade não poderão desempenhar corretamente os seus objetivos, principalmente nos dados coletados sobre áreas com grandes variações laterais de velocidade e com eventos com fortes mergulhos.

Entre as alternativas mais usadas, devido ao grande poder de processamento dos novos computadores, inclui-se a migração antes do empilhamento de dados ordenados em ponto de tiro comum. Outra alternativa também muito utilizada é a migração de dados ordenados em famílias de afastamento comum (Deregowski \& Rocca, 1981) ou a migração parcial antes do empilhamento (Yilmaz \& Claerbout, 1980; Bolondi et al., 1982; Hale, 1984). Este último procedimento consiste na aplicação das correções de NMO e "Dip Moveout" (DMO); entretanto, este método, ainda, não funciona de maneira satisfatória em dados de regiões com variações complexas de velocidade e assim não consegue eliminar os efeitos indesejáveis introduzidos pelo procedimento NMO + EMPILHAMENTO, quando aplicado a dados ordenados em famílias CMP.

Uma discussão teórica sobre migração de dados ordenados em afastamento comum é apresentada por Deregowski \& Rocca (1981). Já Sattlegger et al. (1980) utilizam a migração antes do empilhamento, com o objetivo de estimar velocidades, de seções ordenadas em família de afastamento comum em função da mesma ser menos sensível a pequenos erros no campo de velocidade, do que os métodos de migração de dados registrados em diferentes afastamentos. No caso da migração de seções ordenadas em afastamento comum, pequenos erros no campo de velocidade provocam pequenos deslocamentos dos refletores, que por sua vez não deterioram a qualidade das seções migradas.

A migração de dados ordenados em afastamento comum pode ser implementada de várias maneiras. Yilmaz (1979) apresentou o método de migração antes do empilhamento de dados ordenados em afastamento e ponto médio. Este método é conhecido como migração antes do empilhamento de dupla raiz quadrada. Deregowski (1990) propôs os procedimentos de NMO e DMO seguidos pela migração de velocidade constante (Stolt, 1978). Dubrulle (1983) apresentou um método de migração com velocidade constante de dados em afastamento comum no domínio da freqüência. Ekren \& Ursin (1995) utilizaram o mesmo procedimento de Dubrulle (1983), mas usando a velocidade de empilhamento para meios planos estratificados.

A equação de migração antes do empilhamento nas coordenadas ponto médio e afastamento (Yilmaz, 1979) pode ser reescrita de forma a possibilitar a migração de seções separadas de afastamento comum. 0 trabalho d $\epsilon$ Popovici (1994) apresenta um procedimento para migrar seções de afastamento comum em meios com velocidade constante e também com variação vertical livre de artefatos de migração. Apesar de eliminar os artefatos de migração, o algoritmo por integração direta apresentado por Popovici (1994) é extremamente lentc e a migração de uma única seção de afastamento comum seria realizada num tempo equivalente àquele necessário para migrar todas as seções de afastamento comum, ao mesmo tempo, usando o método apresentado por Yilmaz \& Claerbout (1980). De forma a resolver o problema de demanda computacional exigidc pelo procedimento, Popovici (1994) propõe a utilização do método de fase estacionária para avaliar a integraçãc sobre os números de onda de afastamento.

Nossa contribuição se inicia com a complementação computacional de um algoritmo rápido baseado no método de fase estacionária, para a migração de seções ordenadas em afastamento comum. Através da implementação do método e fase estacionária, conseguimos um desempenho computacional bem melhor do que o obtido pelo algoritmo de integração direta.

A migração de seções separadas de afastamento comum (Popovici, 1994) é realizada através do processo de extrapolação do campo de onda de forma não-recursiva, ou seja, a extrapolação para qualquer nível de profundidade é obtida sempre a partir do campo registrado na superfície. Neste trabalho, também derivamos uma relação que nos possibilitou extrapolar o campo de onda de forma recursiva. Na extrapolação recursiva o campo de onda de um determinado nível é obtido a partir do campo previamente extrapolado. Através deste procedimento de extrapolação, estendemos o método, inicialmente desenvolvido para meios com velocidade constante e verticalmente variável, para meios com variação lateral.

Neste trabalho apresentamos o desenvolvimento teórico e várias aplicações do novo método de migração antes do empilhamento, que passamos a chamar de migração em duas etapas de dados ordenados em afastamento comum. Os algoritmos implementados foram aplicados em dados sintéticos modelados em meios com variação vertical e lateral de velocidade. Também aplicamos o novo método em seções de afastamento comum dos dados Marmousi, dados modelados a partir de uma situação estrutural real complexa, apresentando um campo de velocidade com fortes contrastes laterais de velocidade. 
A migração antes do empilhamento nas coordenadas ponto médio e afastamento para velocidade constante (Yilmaz, 1979) é dada pela seguinte expressão:

$p\left(t=0, k_{y}, h=0, z\right)=\int d \omega \int d k_{h} e^{i k_{z}\left(\omega, k_{y}, k_{h}\right) z} P\left(\omega, k_{y}, k_{h}\right)$,

onde o campo $P\left(\mathrm{w}, k_{y}, k_{h}\right)$ é a transformada tridimensional de Fourier do campo $p(t, y, h)$ registrado na superfície $z=0$.

A phase $k_{z}\left(w, k_{y}, k_{h}\right)$ é definida a partir da relação de dispersão como:

$k_{z}=-\operatorname{sign}(\omega)\left[\sqrt{\frac{\omega^{2}}{v^{2}}-\left(\frac{k_{y}+k_{h}}{2}\right)^{2}}+\sqrt{\frac{\omega^{2}}{v^{2}}-\left(\frac{k_{y}-k_{h}}{2}\right)^{2}}\right]$

que é também conhecida como "Double Square Root (DSR) equation". As integrais em w e $k_{h}$ que aparecem na Eq. (1) representam a condição de imagem para afastamento zero e tempo zero $(h=0, t=0)$.

Migração de Dados Ordenados em Afastamento Comum

A migração antes do empilhamento, via equação DSR, pode ser redefinida de forma a possibilitar a migração de seções separadas de afastamento comum. A transformada de Fourier de um campo de onda 3-D sobre afastamento é

$P\left(\omega, k_{y}, k_{h}\right)=\int d h e^{-i k_{h} h} P\left(\omega, k_{y}, h\right)$.

Substituindo este campo de onda na Eq. (1), a equação de migração antes do empilhamento passa a ser escrita da seguinte forma:

$$
\begin{aligned}
p_{i} & =\int d \omega \int d k_{h} e^{i k_{z}\left(\omega, k_{y}, k_{h}\right) z} \int d h e^{-i k_{h} h} P\left(\omega, k_{y}, h\right) \\
& =\int d h \int d \omega P\left(\omega, k_{y}, h\right) \int d k_{h} e^{i k_{z}\left(\omega, k_{y}, k_{k}\right) z-t k_{h} h},
\end{aligned}
$$

onde $p_{i}=p\left(t=0, k_{h}, h=0, z\right)$. A integral em $h$ soma as seções de afastamento comum migradas individualmente. Agora, sem o passo de soma em $h$, cada seção de afastamento comum ( $h=h_{0}=$ constante), pode ser migrada através da equação DSR, da seguinte forma:

$p\left(t=0, k_{y}, h_{o}, z\right)=\int d \omega P\left(\omega, k_{y}, h_{o}\right) \int d k_{h} e^{i k_{z}\left(\omega, k_{y}, k_{k}\right) z-i k_{h} h_{o}}$,

Segundo Popovici (1994), a migração via equação DSR (Eq. 5) pode ser implementada da seguinte forma, onde a multiplicação do campo de onda $P\left(\mathrm{w}, k_{y} ; h_{0}\right)$ é realizada fora do laço em $k_{h}$, como:

FFT ao longo dos eixos $t \mathrm{e} y \operatorname{de} p\left(t, h ; h_{0}\right) \rightarrow$

$P\left(\omega, k_{y} ; h_{o}\right)$

Calcular para todos os $\omega, k_{y} \mathrm{e} k_{h}$

$$
p h\left(\omega, k_{y}, k_{h}\right)=e^{-k_{h} h_{o}}
$$

do $z$

do $k_{y}$

do $\omega$

do $k_{b}$

$$
p h\left(\omega, k_{y}, k_{h}\right)-p h\left(\omega, k_{y}, k_{h}\right) e^{i k_{z} d_{z}}
$$

phase $\left(\omega, k_{h}\right)=$ phase $\left(\omega, k_{y}\right)+p h\left(\omega, k_{y}, k_{b}\right)$

$M\left(z, k_{y}\right)=M\left(z, k_{y}\right)+P\left(\omega, k_{y}\right) *$ phase $\left(\omega, k_{y}\right)$

O laço em $k_{h}$ torna-se uma integração numérica dos termos exponenciais, integral esta que pode ser aproximada assintoticamente através do uso do método de fase estacionária. No caso de meios com variação vertical de velocidade, temos que somar os termos de fase correspondentes a cada nível de profundidade. Em outras palavras, para meios com velocidade variando com profundidade, o termo exponencial contém a soma de todas as fases correspondentes aos níveis anteriores de profundidade.

O algoritmo acima pode ter seu desempenho computacional bastante melhorado caso uma boa aproximação de fase estacionária seja encontrada para a integral

$I\left(\omega, k_{y}, k_{o}\right)=\int d k_{h} e^{i k_{z}\left(\omega, k_{y}, k_{h}\right) z-i k_{h} h_{o}}$.

Neste caso, o algoritmo passaria a ser 
FFT ao longo dos eixos te $y$ de $p\left(t, h ; h_{o}\right) \rightarrow$

$P\left(\omega, k_{y} ; h_{o}\right)$

Calcular para todos os $\omega, k_{y} \mathrm{e} k_{z}$

$$
p h\left(\omega, k_{y}, k_{h}\right)=e^{-k_{i} h_{o}}
$$

do $z$

do $k_{y}$

do $\omega$

do $k_{b}$

$p h\left(\omega, k_{y}, k_{h}\right)-p h\left(\omega, k_{\gamma}, k_{h}\right) e^{i k_{z} d_{z}}$

phase $\left(\omega, k_{h}\right)=$ phase $\left(\omega, k_{y}\right)+\operatorname{ph}\left(\omega, k_{y}, k_{h}\right)$

$M\left(z, k_{y}\right)=M\left(z, k_{y}\right)+P\left(\omega, k_{y}\right) *$ phase $\left(\omega, k_{y}\right)$

Vale ressaltar que o conhecimento da fase estacionária de certo nível de profundidade não é suficiente para o cômputo do campo no nível seguinte. Este fato limita fortemente este tipo de migração e, por conseguinte, torna o algoritmo de migração antes do empilhamento muito lento, de forma que a migração de uma única seção de afastamento comum seria realizada quase no mesmo tempo necessário para migrar todas as seções de afastamento comum.

Como veremos a seguir, a fase estacionária não pode ser determinada analiticamente, pois isto implica no cálculo das raízes de um polinômio do sexto grau. Assim sendo, uma alternativa viável seria a implementação do método de migração através do uso de um método numérico eficiente para a determinação da integral, Eq. (6), via o método de fase estacionária.

\section{Método de Fase Estacionária}

O procedimento de continuação para baixo usando a equação DSR para seções separadas de afastamento comum requer a computação do núcleo da integral (Eq. (6)), que pode ser avaliada de acordo com o princípio d€ fase estacionária (Born \& Wolf, 1975). Este princípio estabelece que com $\mathrm{f}=\left(k_{z} 3 / 4 k_{h} h / z\right) z$, podemos para $z$ suficientemente grande, usar a seguinte aproximação:

$\int \exp \left[i \phi\left(k_{h}\right)\right] d k_{h} \approx\left[\frac{2 \pi}{\left|\phi^{*}\right|}\right]^{\frac{1}{2}} \exp \left(i\left[\phi\left(\hat{k}_{h}\right)+\operatorname{sign}\left(\phi^{\prime \prime}\left(\hat{k}_{h}\right)\right) \pi / 4\right]\right)$

onde $\hat{k}_{h}$ é o ponto de fase estacionária encontrado através da solução de $\mathrm{f}^{\prime}\left(k_{h}\right)=0$. A aproximação de fase estacionária baseia-se no fato que para $z$ grande e $h$ também pequeno em relação à $z$ ( $|\mathrm{f}|$ torna-se grande) as partes real e imaginária do integrando oscilam rapidamente, gerando contribuição nula para a integral, exceto quando $f^{\prime}=0$.

A aproximação acima considera que a derivada segunda da fase não é nula, que é o caso.

A fase do exponencial é

$\phi\left(k_{h}\right)=-s z\left[\sqrt{\frac{\omega^{2}}{v^{2}}-\left(\frac{k_{y}+k_{h}}{2}\right)^{2}}+\sqrt{\frac{\omega^{2}}{v^{2}}-\left(\frac{k_{y}-k_{h}}{2}\right)^{2}}\right]-k_{h} h$,

onde $s=\operatorname{sign}(\mathrm{w})$. Para calcular a fase estacionária, precisamos encontrar as raízes da equação

$\phi^{\prime}\left(k_{h}\right)=0$,

onde

$\phi^{\prime}\left(k_{h}\right)=\frac{s z}{4}\left[\frac{k_{h}+k_{y}}{\sqrt{\frac{\omega^{2}}{v^{2}}-\left(\frac{k^{+}+k}{2}\right)^{2}}}+\frac{k_{h}-k_{y}}{\sqrt{\frac{\omega^{2}}{v^{2}}-\left(\frac{k^{-k} h}{2}\right)^{2}}}\right]-h$.

No caso da fase acima, verifica-se que a derivada segunda é não nula e contém quatro termos positivos: 


$$
\begin{aligned}
\phi^{\prime \prime}\left(k_{h}\right) & =\frac{\operatorname{sign}(\omega) z}{4} \mid \frac{1}{\sqrt{\frac{\omega^{2}}{v^{2}}-\left(\frac{k^{k} y^{-k} h}{2}\right)^{2}}}+\frac{\left(k_{h}-k_{y}\right)^{2}}{4\left[\frac{\omega^{2}}{v^{2}}-\left(\frac{k^{k} y^{-k}}{2}\right)^{2}\right]^{3 / 2}} \\
& \left.+\frac{1}{\sqrt{\frac{\omega^{2}}{v^{2}}-\left(\frac{{ }^{k}+k_{h}}{2}\right)^{2}}}+\frac{\left(k_{h}+k_{y}\right)^{2}}{4\left[\frac{\omega^{2}}{v^{2}}-\left(\frac{{ }^{k} y+k}{2}\right)^{2}\right]^{3 / 2}}\right] .
\end{aligned}
$$

Este fato assegura que não existe mudança de curvatura e a fase tem pelo menos um máximo ou um mínimo e portanto um ponto de fase estacionária. A partir desta propriedade, passamos a desenvolver um algoritmo para encontrar a fase estacionária via o método de Newton (método de determinação de raízes). 0 algoritmo escolhido para este fim é bastante rápido, tornando possível a migração de dados de afastamento comum de forma eficiente, sob o ponto de vista computacional.

\section{MEIOS PLANOS ESTRATIFICADOS}

Em meios planos estratificados, o termo de fase que era dado por

$\exp \left(i k_{z} z\right)$ torna-se $\exp \left(\int_{0}^{z} k_{z} d z^{\prime}\right)$

onde

$k_{z}=-\operatorname{sign}(\omega)\left[\sqrt{\frac{\omega^{2}}{v(z)^{2}}-\left(\frac{k_{y}+k_{h}}{2}\right)^{2}}+\sqrt{\frac{\omega^{2}}{v(z)^{2}}-\left(\frac{k_{y}-k_{h}}{2}\right)^{2}}\right]$

Mais uma vez podemos empregar o princípio da fase estacionária, de forma a resolver a integral

$I\left(\omega, k_{y}, h, z\right)=\int d k_{h} e^{i \int_{0}^{z} k_{z}\left(\omega, k_{y}, k_{h}, z^{\prime}\right) d z^{\prime}} e^{-i k_{h} h}$

Agora, a integral acima incorpora a soma das fases correspondentes às diferentes fatias de profundidade.

Definindo-se

$G(k, z)=\int_{0}^{2} \sqrt{\frac{\omega^{2}}{v\left(z^{\prime}\right)^{2}}-k^{2} d z^{\prime}}$

temos que $\left.\int_{0}^{z} k_{z} d z^{\prime}=G_{1} \frac{1}{2}\left(k_{y}-k_{h}\right)\right]+G\left[\frac{1}{2}\left(k_{y}+k_{h}\right)\right]$ e a fase dada por $\phi=\int_{0}^{z} k_{z} d z^{\prime}-k_{h} h$ Os pontos de fase estacionária são encontrados através da solução de $\mathrm{f}^{\prime}=0$, que é dado por

$-\frac{1}{2} G^{\prime}\left[\left(k_{y}-\hat{k}_{h}\right)\right]+\frac{1}{2} G^{\prime}\left[\left(k_{y}+\hat{k}_{h}\right)\right]-h=0$,

com

$G^{\prime}(k, z)=\int_{0}^{z} \frac{k}{\sqrt{\frac{\omega^{2}}{v\left(z^{\prime}\right)^{2}}-k^{2}}} d z^{\prime}=-F(k, z)$.

A equação a ser resolvida para determinação do ponto de fase estacionária é

$2 h=F\left[\left(\frac{1}{2}\left(k_{y}-\hat{k}_{h}\right)\right]-F\left[\frac{1}{2}\left(k_{y}+\hat{k}_{h}\right)\right]\right.$.

Como no caso de velocidade constante, o valor de $\hat{k}_{h}$ também não pode ser determinado algebricamente. $\mathrm{E}$, além disso, a solução da Eq. (18) através de um método numérico seria muito demorado computacionalmente. Então, optamos por substituir a velocidade variável com profundidade pela velocidade equivalente de cada profundidade a ser migrada e determinar a integral, usando o mesmo algoritmo de fase estacionária desenvolvido para o caso de velocidade constante. O fato de substituir as velocidades das camadas por uma velocidade equivalente não acarreta erros no processo de migração, como mostraremos através dos vários exemplos sintéticos, na parte que discute os resultados numéricos. 


\section{MEIOS COM VARIAÇÃO LATERAL}

Visando diminuir o erro no processo de continuação do campo para cada nível em profundidade, devido a substituição das velocidades das camadas pela velocidade média equivalente até o nível a ser migrado, escolhemos fazer a continuação do campo de onda de forma recursiva e assim corrigir as variações laterais presentes no campo de velocidade.

O apêndice $A$ mostra como desenvolvemos os cálculos com o objetivo de encontrar uma expressão que nos possibilitasse obter o campo $P\left(\mathrm{w}, k_{y}, z+\mathrm{D} z\right)$ em função do campo $P\left(\mathrm{w}, k_{y}, z\right)$ e chegamos à seguinte expressão:

$P\left(\omega, k_{y}, h, z_{2}\right)=P\left(\omega, k_{y}, h, z_{1}\right) \sqrt{\frac{\phi^{\prime \prime}\left(\hat{k}_{h 2}\right)}{\phi^{\prime \prime}\left(\hat{k}_{h 1}\right)} \frac{e^{i \int_{0}^{z_{2}} k_{z^{\prime}}\left(\hat{k}_{k 2}\right) d z^{\prime}} e^{-i \hat{k}_{b 2} h}}{e^{i \int_{0}^{z_{1}} k_{z^{\prime}}\left(\hat{k}_{h 1}\right) d z^{\prime}} e^{-i \hat{k}_{h 1} h}}}$,

onde $\hat{k}_{h l}$ e $\hat{k}_{h 2}$ são os valores de $k_{h}$ que tornam a fase $\phi\left(k_{h}\right)=\int_{0}^{z} k_{z^{\prime}} d z^{\prime}-k_{h} h$ estacionária.

A Eq. (19) será usada agora para fazer a continuação para baixo do campo de onda. Ela possibilita a determinação do campo no nível $z+\mathrm{D} z$, a partir do campo no nível $z$. Para tanto, precisamos determinar o valo $\hat{k}_{h}$ de que é o valor de $k_{h}$ que torna a fase estacionária. O valor de $\hat{k}_{h}$ é calculado substituindo-se a velocidade das camadas até o nível $z$, pela correspondente velocidade média (média de cada fatia ao longo da direção $y$ ) até a referida profundidade. $\mathrm{O}$ cálculo de $\hat{k}_{h}$ considerando as várias velocidades até a profundidade a ser migrada seria bastante demorado e tornaria o método inviável computacionalmente. Esta é a principal razão para considerarmos a velocidade média equivalente no momento do cálculo da fase estacionária.

Após a extrapolação do campo $P\left(\mathrm{w}, k_{y}, h, z\right)$ para o nível $z+\mathrm{D} z$, através Eq. (19), aplicamos ao campo extrapolado uma correção "split-step". O método "split-step" baseia-se na aplicação de uma correção "phaseshift" ao campo extrapolado, correção que tem como finalidade corrigir as variações laterais. Stoffa et al. (1990 fizeram uso deste tipo de correção em seções de afastamento nulo e obtiveram bons resultados em dados reais, mesmo em meios com fortes contrastes laterais de velocidade.

Em seções de afastamento comum, o termo de correção "split-step" (Apêndice B) é dado por

$e^{i\left(\frac{2}{v_{w}(z)}-\frac{1}{v(y-h, z)}-\frac{1}{v(y+h, z)}\right) \omega \Delta z}$

Então, para cada ponto-médio $(y)$, usamos a velocidade na posição $y 3 / 4 h$ (posição da fonte) e a velocidade na posição $y+h$ (posição do receptor). Como na equação DSR a velocidade é definida nas coordenadas da fonte e do receptor, podemos facilmente ir para as coordenadas $(y, h)$, ponto médio e afastamento, usando as relações de transformação $y=\frac{x_{g}+x_{s}}{2}$ e $h=\frac{x_{g}-x_{s}}{2}$, onde $x_{s}$ e $x_{g}$ são respectivamente as coordenadas da fonte e do receptor. Note que $h$ é a metade da distância entre fonte e receptor.

O método com a inclusão do termo de correção "split-step" consiste em aplicar uma primeira correção de fase no domínio $(w, k y, h)$ usando uma velocidade de referência. Em seguida, uma segunda correção (Eq. 20) é aplicada após os dados serem convertidos para o domínio ( $w, y, h)$ com o objetivo de considerar a variação lateral presente no campo de velocidade.

Assim, a partir do campo $\mathrm{P}\left(\mathrm{w}, k_{y}, h, z\right)$ obtemos $p(t=0, y, h, z)$ através da transformada inversa de Fourier em $k_{y}$ e da soma de w, isto é,

$p(t=0, h, z)=\sum_{\omega} \sum_{k_{i}} P\left(\omega, k_{y}, h, z\right) \exp \left(i k_{y} y\right)$,

onde $p(t=0, y, h, z)$ é a seção de afastamento constante, migrada em profundidade através de um procedimento que considera as variações laterais presentes no campo de velocidade.

\section{RESULTADOS NUMÉRICOS}

Nesta seção apresentaremos os resultados obtidos com a técnica de migração para afastamento comum. Para os testos dos algoritmos desenvolvidos, escolhemos um modelo de cinco refletores com diferentes inclinações e também os dados Marmousi, devido à sua complexidade estrutural e fortes variações laterais de velocidade.

Inicialmente aplicamos o método de migração para um meio de velocidade constante igual a $3500 \mathrm{~m} / \mathrm{s}$. A Fig. 1a mostra o modelo em profundidade dos refletores escolhidos para testar o método. Este modelo apresenta quatro refletores com diferentes inclinações e um refletor plano na profundidade de $3000 \mathrm{~m}$. A Fig. $1 \mathrm{~b}$ mostra a seção em tempo de afastamento $2000 \mathrm{~m}$, obtida através do programa de modelagem "SUSYLNV" (programa para fazer modelagem em meios com variação linear de velocidade) do pacote "Seismic Unix" (US) do "Center for 
Wave of Phenomena (CWP). Na Fig. 1c mostramos o resultado da migração com o nosso método para a seção de afastamento nulo $(\mathrm{h}=0$ ) e na Fig. 1d o resultado para o afastamento $2000 \mathrm{~m}$. Neste caso, verifica-se o perfeitc posicionamento dos refletores e o efeito de estiramento na seção de afastamento $2000 \mathrm{~m}$ (Fig. 1d), efeitos presentes nos eventos rasos das seções de grande afastamento nas migrações antes do empilhamento.

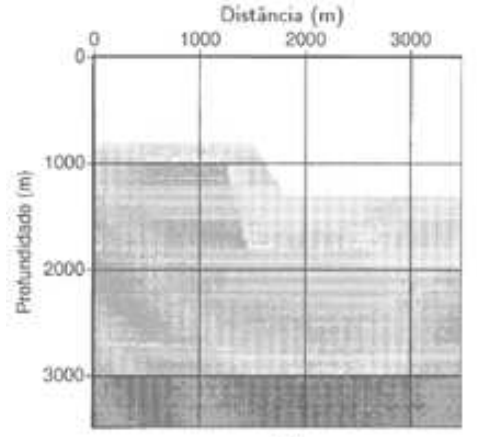

(a)

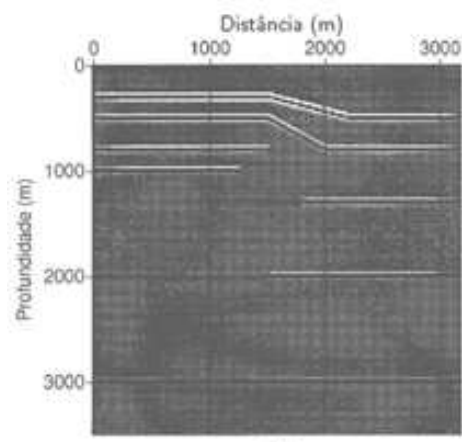

(c)

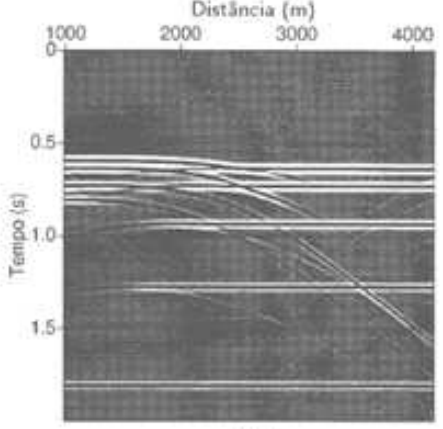

(b)

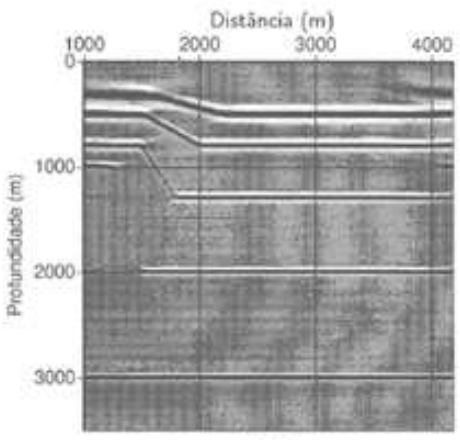

(d)

Figura 1 - Resultados obtidos para velocidade constante: a) modelo dos refletores em profundidade; b) seção de afastamento comum igual a 2000 m; c) Resultado da migração da seção de afastamento nulo; d) resultado da migração da seção mostrada na Fig. 1 b.

Figure 1 - Results for constant velocity media: a) model of reflectors in depth; b) section of constant offset of $2000 \mathrm{~m}$; c) results of migration of the section of zero offset; d) result of migration of the data shown in Fig. $1 \mathrm{~b}$.

Com o mesmo modelo dos refletores em profundidade (Fig. 1a), testamos o método para o caso em que o campr de velocidade apresenta uma variação vertical. Na Fig. 2 a mostramos o modelo de velocidade, com variação vertical (de 3500 a $6300 \mathrm{~m} / \mathrm{s}$ ). A seção em tempo de afastamento constante de $2000 \mathrm{~m}$ é apresentada na Fig. $\underline{2 b}$. Nesta seção, a reflexão referente ao refletor na profundidade de $2000 \mathrm{~m}$ aparece no temp de $1,4 \mathrm{~s}$, enquanto na seção de velocidade constante (Fig. 1b) ela aparece no tempo de 1,8 s. O resultado da migração di seção de afastamento nulo, para este campo de velocidade, é mostrado na Fig. 1c com os refletores corretamente posicionados. Na Fig. 2 d temos a migração da seção mostrada na Fig. 2 b $3 / 4$ seção de afastamento de $2000 \mathrm{~m}$, utilizando o campo de velocidade da Fig. 2a. Os resultados mostram que o método consegue posicionar perfeitamente os refletores, mesmo na presença de variação vertical de velocidade para os afastamentos 0 e $2000 \mathrm{~m}$, de forma similar ao obtido para velocidade constante (Fig. 1d). 


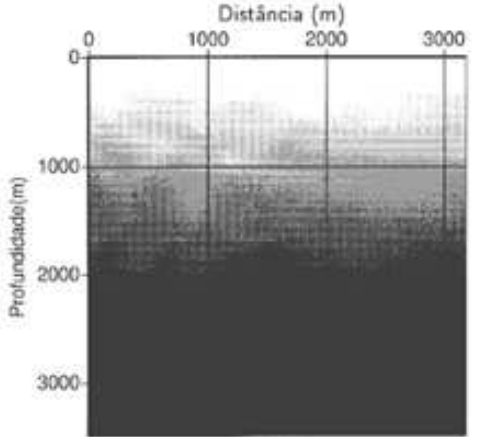

(a)

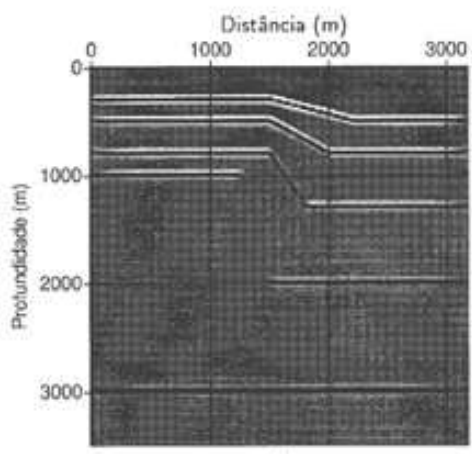

(c)

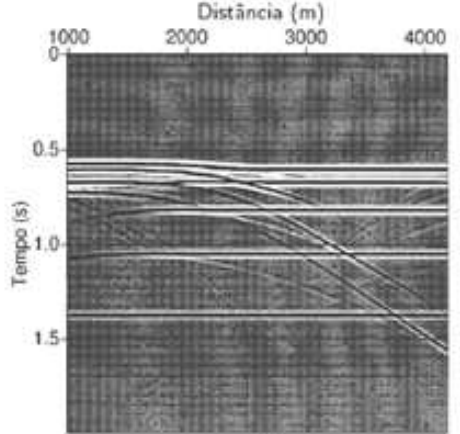

(b)

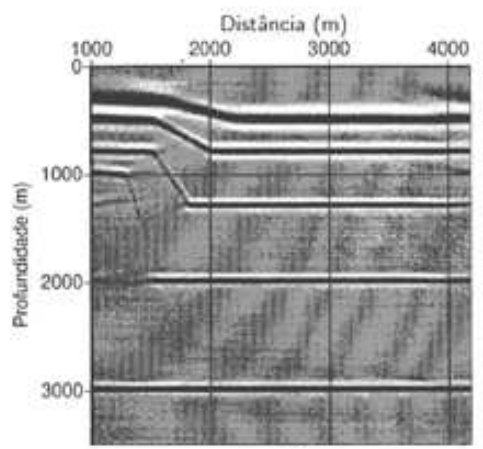

(d)

Figura 2 - Resultados obtidos para velocidade com variação vertical: a) modelo de velocidade; b) seção de afastamento comum igual a 2000 m; c) resultado da migração da seção de afastamento nulo; d) resltado da migração dos dados da Fig. 2 b com o campo de velocidade mostrado na Fig. 2 b.

Figure 2 - Results for velocity field with vertical variation: a) model of velocity; b) section of constant offset of $2000 \mathrm{~m}$; c) result of migration of the section of zero offset; d) result of migration of the data of Fig. $2 b$ with velocity field shown in Fig. 2 a.

Em seguida, testamos o método na presença de campos de velocidade com variação lateral. Para este fim utilizamos novamente o modelo de refletores em profundidade (Fig. 1a), colocado sobre um campo de velocidade com variação lateral. Na Fig. 3a mostramos o campo de velocidade a ser usado para os nossos testes O campo de velocidade apresenta um gradiente vertical de $0,8 \mathrm{~s}^{-1}$ e lateral de $0,2 \mathrm{~s}^{-1}$, de forma a apresentar uma faixa de variação de velocidade de 2500 a 9050 m/s. Na Fig. 3b temos a seção em tempo de afastamento nulo, modelada a partir deste modelo de velocidade com os refletores posicionados em profundidade, como mostrado na Fig. 1a. Com este campo de velocidade lateralmente variável, as reflexões na seção em tempo, referentes aos refletores planos, se apresentam agora inclinadas. 


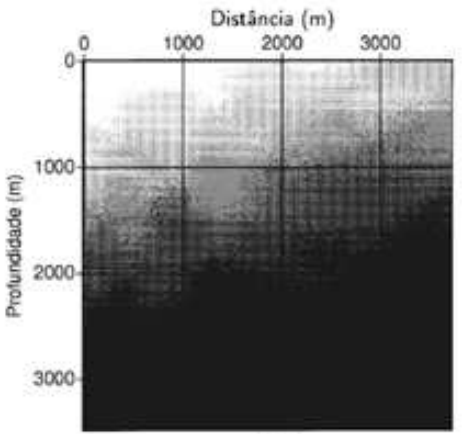

(a)

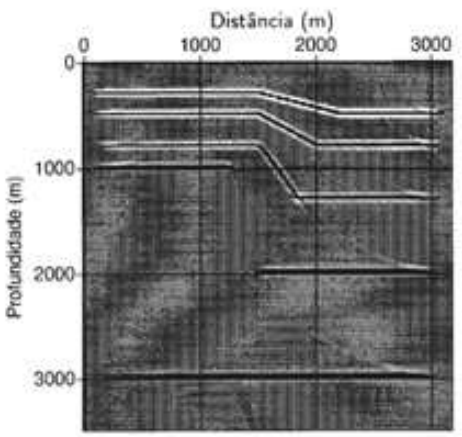

(c)

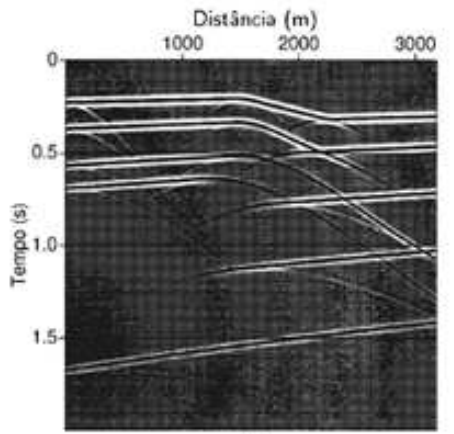

(b)

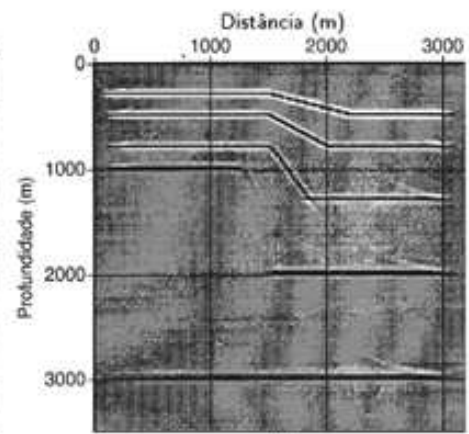

(d)

Figura 3 - Resultados obtidos para velocidade com variação vertical e lateral fraca: a) modelo de velocidade com gradiente vertical de $0,8 \mathrm{~s}^{-1}$ e lateral de $0,2 \mathrm{~s}^{-1}$; b) seção de afastamento nulo; c) resultado da migração dos dados da Fig. 3c com o método "split-step"; d) resultado da migração dos dados mostrados na Fig. 3b com c novo método.

Figure 3 - Results for velocity field with vertical and weak lateral velocity variation; a) model of velocity with vertical gradient of $0.8 \mathrm{~s}^{-1}$ and $0.2 \mathrm{~s}^{-1}$ of lateral gradient; b) section of zero offset. c) result of migration of the data show in Fig. $3 \mathrm{~b}$ using the split-step migration method. d) rresult of migration of the data of Fig. $3 \mathrm{~b}$ using the new migration method.

Para efeito de comparação, utilizamos a técnica "split-step" (Stoffa et al., 1990), válida para afastamento nulo e comparamos os resultados apresentados pelos dois métodos. A Fig. 3c mostra o resultado do algoritmo "splitstep", aplicado à seção de afastamento nulo (Fig. 3b). A Fig. 3d é o resultado obtido com o nosso método. Comparando-se os dois resultados (Figs. $3 \mathrm{c}$ e $\underline{3 \mathrm{~d}}$ ), verifica-se que ambos os métodos posicionaram corretament $\epsilon$ os refletores (Fig. 1a). É importante ressaltar que os dois algoritmos, diferentes na forma de implementação, quando aplicados aos mesmos dados (Fig. 3b), conseguem posicionar os refletores nas suas verdadeiras profundidades.

Ainda na presença de contrastes laterais de velocidade, verificamos o desempenho do método proposto neste trabalho para os afastamentos 500 e $2000 \mathrm{~m}$. Na Fig. 4a temos a seção em tempo de afastamento $2000 \mathrm{~m}$ e na Fig. 4b o resultado da migração dos dados de afastamento comum de $500 \mathrm{~m}$, com o modelo de velocidade mostrado na Fig. 3a. Já o resultado da migração da seção de afastamento 2000 (Fig. 4a) é apresentado na Fig. 4c. Analisando os resultados encontrados para os dados de afastamento de 500 e 2000 m (Figs. 4b e 4c), respectivamente, podemos garantir que o método funciona bem para o afastamento de $500 \mathrm{~m}$ se compararmos com o resultado apresentado pela migração de afastamento nulo (Fig. 3d). Nota-se na Fig. 4b o correto posicionamento dos refletores. O resultado para o afastamento 2000 também apresenta os refletores profundos corretamente posicionados, enquanto os refletores mais rasos estão totalmente comprometidos devido ao estiramento inerente ao método de migração antes do empilhamento. Normalmente, antes de se efetuar a migração aplica-se um corte ("mute") nas seções de grande afastamento, evitando-se assim o efeito de estiramento. 


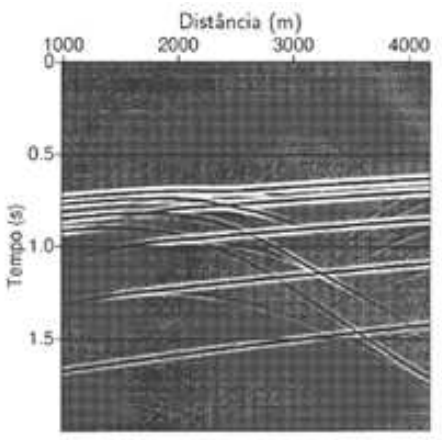

(a)

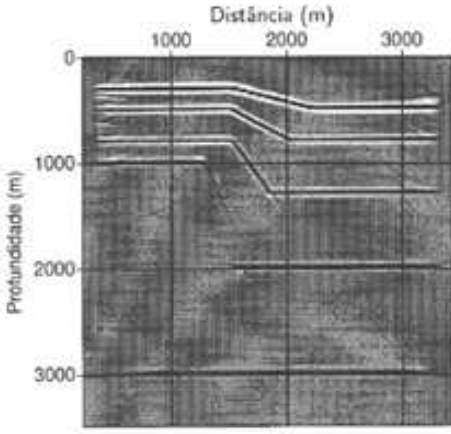

(b)

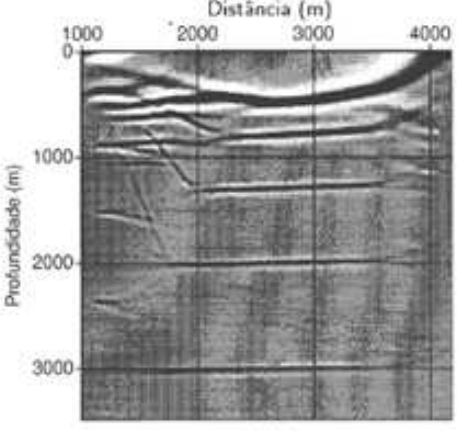

(c)

Figura 4 - Resultados obtidos para velocidade com variação vertical e lateral fraca: a) seção de afastamento comum igual a $2000 \mathrm{~m}$ para o mesmo campo de velocidade apresentado na Fig. 3a; b) resultado da migração da seção de afastamento comum igual a 500 m; d) resultado da migração dos dados da Fig. 4a, usando o campo de velocidade mostrado na Fig. 3 a.

Figure 4 - Results for velocity field with vertical and weak lateral velocity variation: a) section of constant offset of $2000 \mathrm{~m}$ from the velocity model shown in Fig. 3a; b) result of migration of the section with a constant offset of $500 \mathrm{~m}$; c) result of migration of the data shown in Fig 4 a using the velocity model of Fig. $3 a$.

Usando o mesmo modelo de profundidade (Fig. 1a), testamos o método para um contraste lateral de velocidade ainda mais forte. Usando um gradiente vertical de velocidade de $0,8 \mathrm{~s}^{-1}$ e lateral de $0,8 \mathrm{~s}^{-1}$, verificamos o desempenho do método para os afastamentos 500 e $2000 \mathrm{~m}$. Na Fig. 5a temos o campo de velocidade, para os gradientes citados acima, e a seção de afastamento 2000 m é mostrada na Fig. 5b, onde se observa uma maior inclinação das reflexões, quando comparada com a seção em tempo de mesmo afastamento apresentada na Fig. 4a. Nas Figs. 5c e 5d temos os resultados das migrações para os afastamentos 500 e 2000 m, respectivamente. $O$ resultado encontrado para os dados de afastamento de $500 \mathrm{~m}$, para este contraste lateral, é ainda muito bom Entretanto, o resultado apresentado para o afastamento de $2000 \mathrm{~m}$ (Fig. $5 \mathrm{~d}$ ) mostra que o método não funcioni bem, ficando comprometida a qualidade dos resultados. 


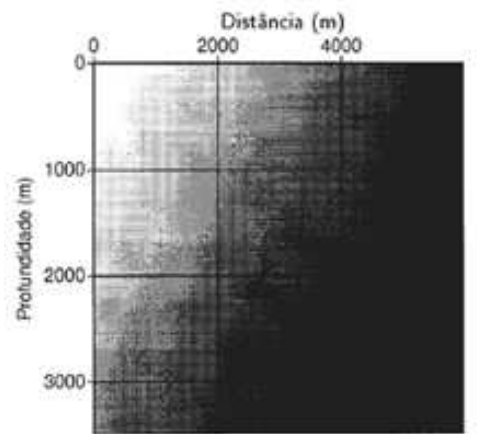

(a)

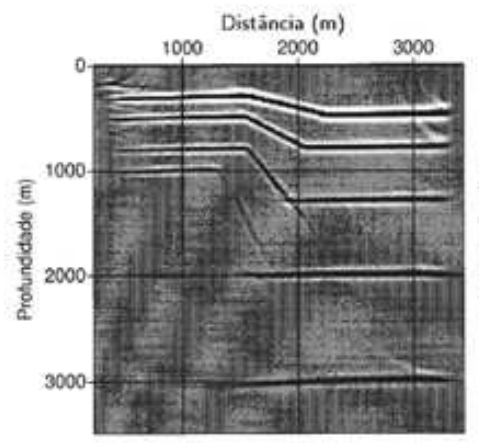

(c)

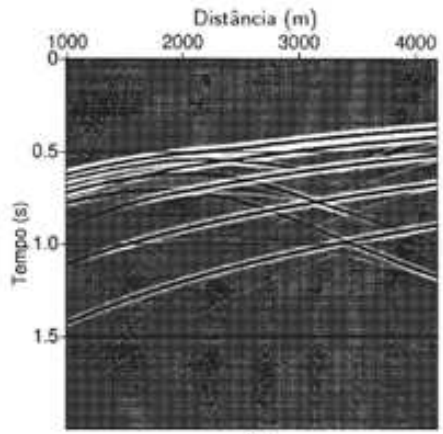

(b)

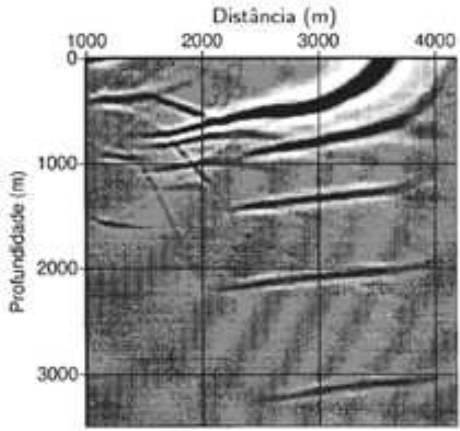

(d)

Figura 5 - Resultados obtidos para velocidade com variação vertical e lateral forte: a) modelo de velocidade com gradiente vertical e lateral de $0,8 \mathrm{~s}^{-1}$; b) seção de afastamento comum igual a $2000 \mathrm{~m}$; c) resultado da migração da seção de afastamento zero; d) resultado da migração dos dados da Fig. 5b, usando o campo de velocidade mostrado na Fig. 5 a.

Figure $\mathbf{5}$ - Results for velocity field with vertical and strong lateral variation: a) velocity model with vertical and lateral gradiente of $0.8 \mathrm{~s}^{-1}$; b) section of constant offset of $2000 \mathrm{~m}$; c) results of migration of the data shown in Fig. 5 b using velocity field presented in Fig. $5 a$.

Após os testes com dados sintéticos, utilizamos os dados Marmousi, muito utilizados na literatura geofísica, gerados a partir de um modelo estrutural bastante complexo. 0 campo de velocidade, mostrado na Fig. $6 \mathrm{com}$ velocidades na faixa de $1,5 \mathrm{~km} / \mathrm{s}$ a $5,5 \mathrm{~km} / \mathrm{s}$, apresenta fortes contrastes laterais de velocidade, tal qual uma situação real. O modelo de velocidade possui 369 por 750 amostras, espaçadas horizontalmente de $25 \mathrm{~m}$ e verticalmente de $4 \mathrm{~m}$. Na Fig. 7 temos a seção em tempo de afastamento mais próximo (200 m). Esta seção possui 240 traços de 726 amostras em tempo, amostrados em tempo a uma taxa de $4 \mathrm{~m}$ e espaçados horizontalmente de $25 \mathrm{~m}$.
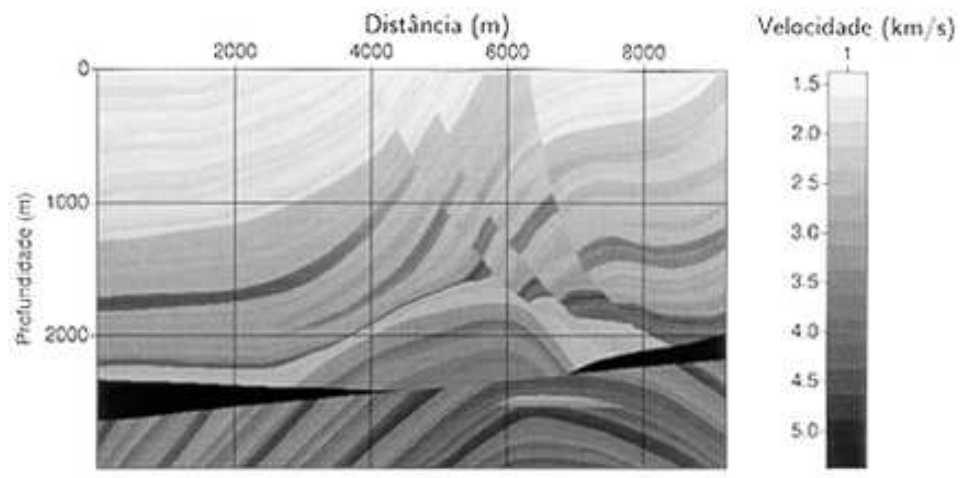

Figura 6 - Modelo de velocidades para os dados Marmousi com os refletores em profundidade para a migração. Figure 6 - Velocity model of the Marmousi data and the location of the reflectors in depth to perform the migration. 


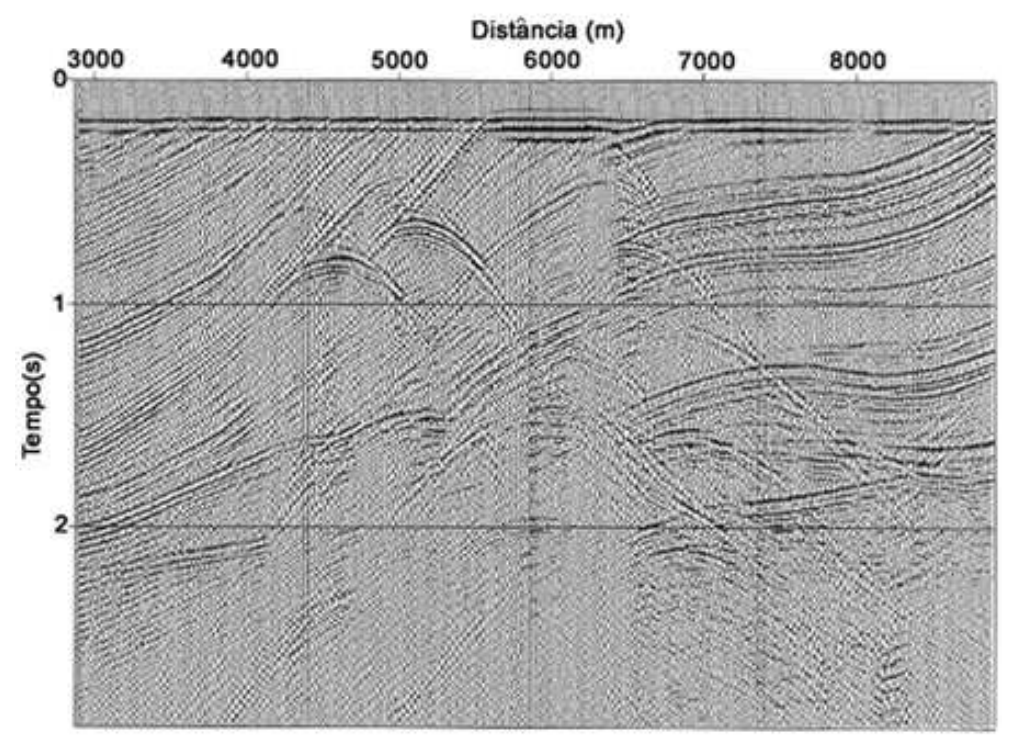

Figura 7 - Seção de afastamento comum de 200 m (afastamento mais curto) dos dados Marmousi. Figure 7 - Section of constant offset of $200 \mathrm{~m}$ (near offset) of the Marmousi data set.

Nas Figs. 8 e 9 mostramos os resultados das migrações "split-step" e do nosso método, respectivamente, tendo como entrada para ambas as migrações os dados mostrados na Fig. 7 e o campo de velocidade apresentado na Fig. 6. O resultado apresentado pelo nosso método, Fig. 9), mostra-se superior ao obtido pelo método "splitstep", Fig. 8. Com o nosso método, as falhas ficaram bem mais definidas e na parte central da seção migrada nota-se uma melhor definição dos refletores, comparado ao resultado mostrado pela Fig.8 (migração "split-step" da seção de afastamento $200 \mathrm{~m}$ ). Vale ressaltar que o algoritmo "split-step" é teoricamente válido para seções de afastamento nulo.

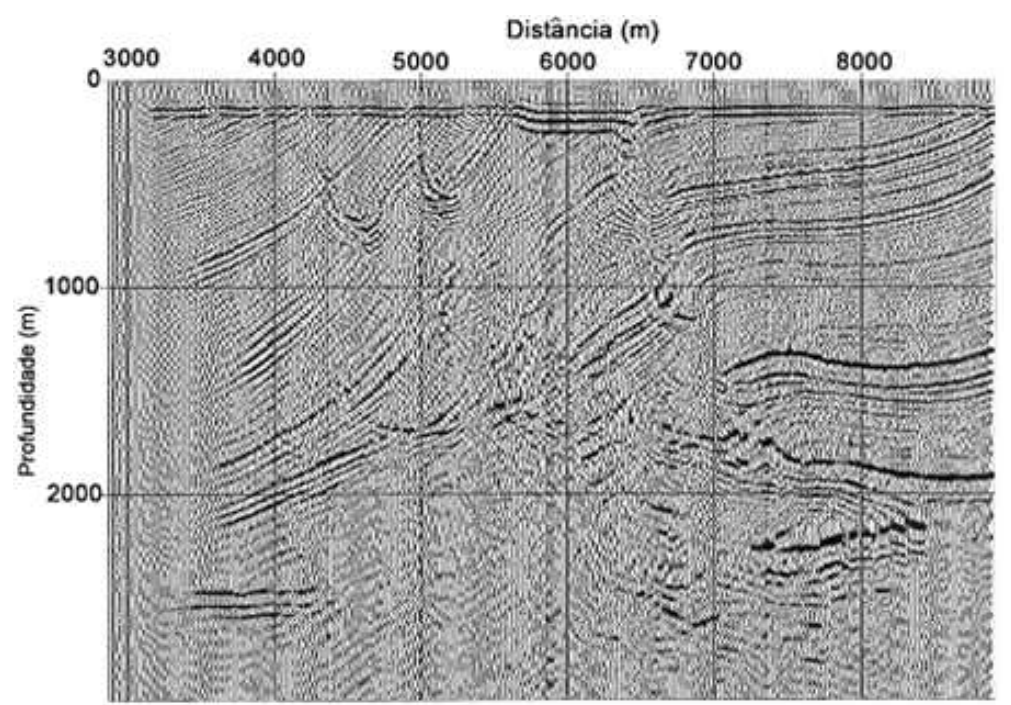

Figura 8 - Resultado da migração dos dados mostrados na Fig. 7 usando o método "split-step". Figure 8 - Result of migration of the data shown in the Fig. 7 using the split-step method. 


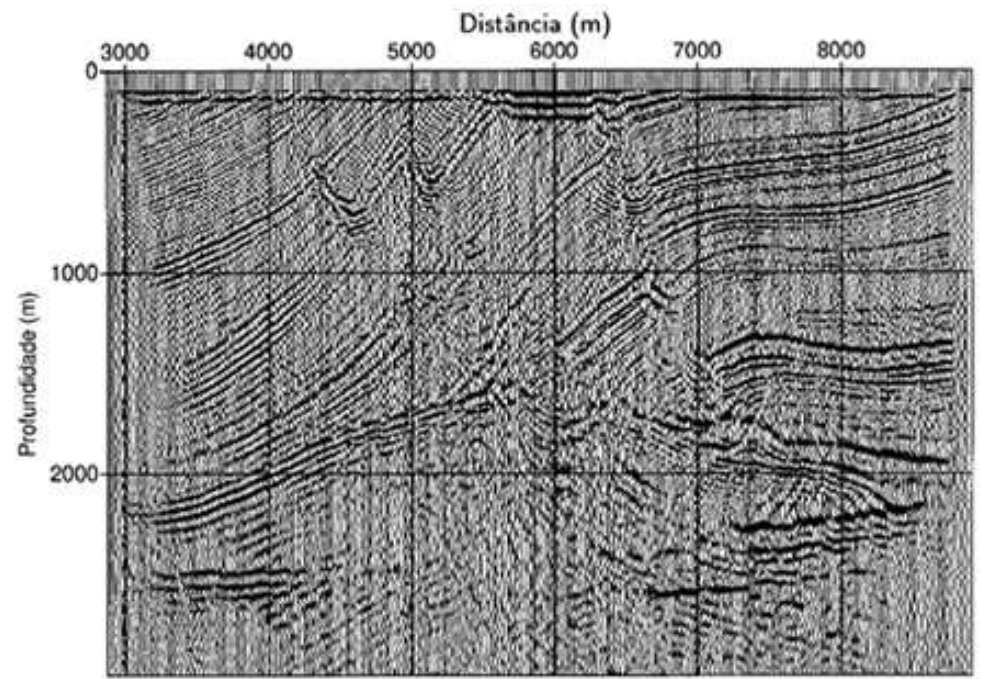

Figura 9 - Resultado da migração dos dados da Fig. 7 usando o novo método.

Figure 9 - Result of migration of the data of Fig. 7 using the new method.

Na Fig. 10, apresentamos uma seqüência de seções migradas para diferentes afastamentos. Nas Figs. $10 \mathrm{a}, \underline{10 \mathrm{~b}}$ e $10 \mathrm{c}$ mostramos os resultados das migrações para os afastamentos de 250,350 e $500 \mathrm{~m}$, rspectivamente. A Fig. $10 \mathrm{~d}$ apresenta o resultado do empilhamento das seções migradas para os afastamentos de 200, 250, 300, $350,400,450$ e $500 \mathrm{~m}$. A partir das Figs. 10a, 10b e 10c, verifica-se que a qualidade dos resultados das migrações dos dados Marmousi vai diminuindo à medida em que cresce o afastamento. Ou seja, a migração do afastamento $500 \mathrm{~m}$ (Fig. 10c) apresenta um resultado inferior a migração do afastamento $250 \mathrm{~m}$ (Fig. $10 \mathrm{a}$ ). 0 resultado apresentado pela Fig. $10 \mathrm{~d}$ mostra que o empilhamento das migrações, considerando-se apenas os afastamentos mais curtos, preserva os principais refletores, validando o método apresentado neste trabalho, para afastamentos curtos em estruturas complexas em subsuperfície.

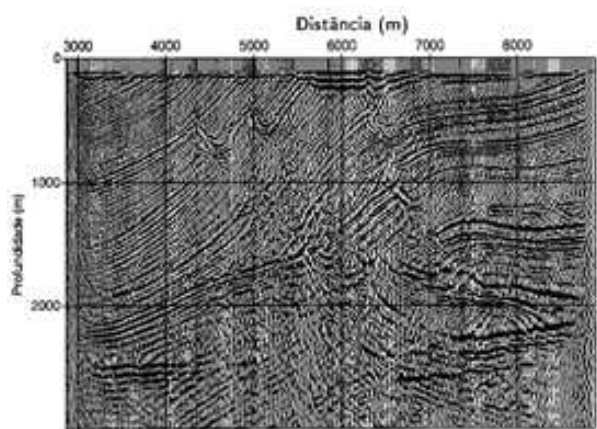

(a)

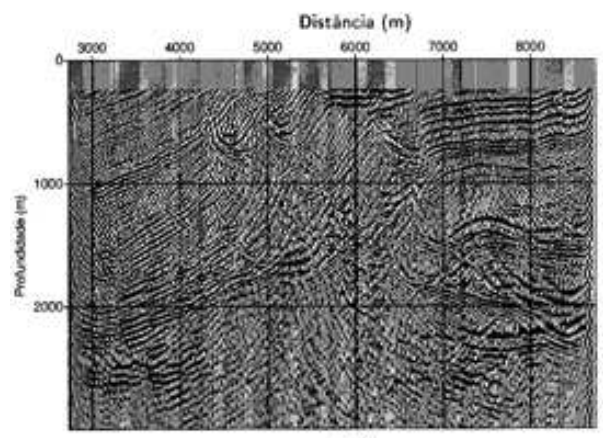

(c)

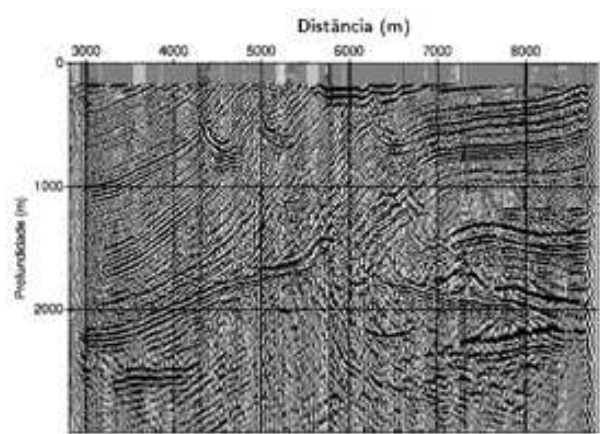

(b)

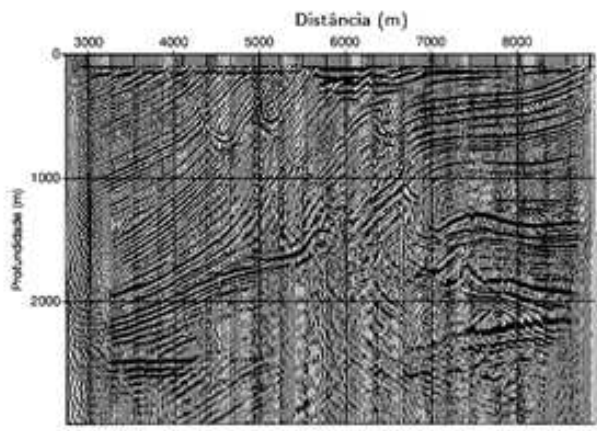

(d)

Figura 10 - Resultados das migrações de seções de diferentes afastamentos e seção empilhada após as migrações. a) Resultado da migração da seção de afastamento igual a 250 m. b) Migração da seção de afastamento igual a $350 \mathrm{~m}$. c) Migração da seção de afastamento igual a $500 \mathrm{~m}$. d) Resultado do empilhamento das seções de afastamentos de 200, 250, 300, 350, 400, 450 e 500 m após a migração.

Figure 10 - Results of the migration of the sections with differents offset and stack after migration. a) Result of Migration of the section of constant offset of $250 \mathrm{~m}$. b) Migration of the section of constant offset of $350 \mathrm{~m}$. c) Migration of the section of constant offset of $500 \mathrm{~m}$. d) Result of stack of the sections of offset 200, 250, 300, 350, 400, 450, $500 \mathrm{~m}$ after migration. 


\section{CONCLUSÃO}

Este trabalho apresenta um método de migração antes do empilhamento de dados sísmicos de seções de afastamento comum em meios com variação vertical e lateral de velocidade. As seções de afastamento comum são migradas separadamente através da equação de dupla raiz quadrada e a integração dos números de ondas de afastamento é avaliada pelo método de fase estacionária. Através da utilização de uma implementação computacional eficiente para o cálculo da fase estacionária, conseguimos melhorar o desempenho computaciona do nosso método de migração em relação ao método de integraçào direta apresentado por Popovici (1994). Neste trabalho também derivamos uma relação que possibilitou a extrapolação do campo de onda de forma recursiva. Na extrapolação recursiva em profundidade, o campo de onda de um nível qualquer é obtido a partir do campo do nível anterior. Com este procedimento recursivo foi possível estender o método, inicialmente desenvolvido para meios com apenas variação vertical de velocidade, para meios com variação lateral. A correção lateral utilizada é do tipo "split-step", correção que visa compensar as variações laterais existentes no campo de velocidade. Nosso trabalho apresenta várias aplicações do método desenvolvido em dados sintéticos modelados em meios com variação vertical e lateral de velocidade. Os resultados demonstram a validade do método em meios com variação vertical de velocidade para os afastamentos utilizados. Nos modelos gerados com variação vertical e lateral suaves, os resultados também indicam que o nosso método ainda consegue produzir boas imagens com os refletores posicionados corretamente. Já os dados Marmousi, devido à sua complexidade estrutural e com um campo de velocidade com fortes contrastes laterais, os resultados obtidos com o novo método ainda são razoáveis para os afastamentos curtos. Mas, a partir dos afastamentos maiores, a qualidade das imagens obtidas começa a diminuir, validando o nosso método para os afastamentos curtos em estruturas complexas e com fortes variações laterais de velocidade.

\section{AGRADECIMENTOS}

Os autores agradecem à Petrobras e ao PPPG/UFBa que proporcionaram a realização desta pesquisa. Reynam Pestana agradece também ao CNPq pelo apoio através de Bolsa de Pesquisa, projeto 300312/88-1 (RE).

\section{REFERÊNCIAS}

BOLONDI, G., LOINGER, E. \& ROCCA, F. - 1982 - Offset continuation of seismic sections. Geophysical Prospecting, 30:813-828. [ [Links ]

BORN \& WOLF - 1975 - Principles of Optics. Pergamon Press, New York. [ Links ]

CLAERBOUT, J. C. - 1985 - Imaging the earth's interior. Blackwell Scientific Publ. [ Links ]

DEREGOWSKI, S. M. \& ROCCA, F. - 1981 - Geometrical optics and wave theory of constant-offset sections in layered media. Geophysical Prospecting, 29:374-406. [ Links ]

DEREGOWSKI, S. M. - 1990 - Common-offset migrations and velocity analysis. First Break, 8:225-234. [ Links ]

DUBRULLE, A. A. - 1983 - Numerical methods for the migration of constant-offset sections in homogeneous and horizontally layered media. Geophysics, 48:1195-1203. [ Links ]

EKREN, B. O. \& URSIN, B. - 1995 - Frequency-wavenumber constant-offset migration and AVO analysis. $65^{\text {th }}$ Ann. Internat. Mtg., Soc. Expl. Geophys., Expanded Abstracts, 1377-1380. [ Links ]

GAZDAG, J. - 1978 - Wave-equation migration with the phase-shift method. Geophysics, 43:1324-1351. [ Links ]

HALE, I. D. - 1984 - Dip-moveout by Fourier transform. Geophysics, 49:741-757. [ Links ]

POPOVIC, A. M. - 1994 - Reducing artifacts in prestack phase-shift migration of common-offset gathers. 64th Ann. Internat. Mtg., Soc. Expl. Geophys., Expanded Abstracts, 684-687. [ Links ]

RISTOW, D. \& RUHL, T. - 1994 - Fourier finite-difference migration. Geophysics, 59:1882, 1893. [ Links ]

SATtlegger, J. W., STiller, P. K., ECHTERHOfF, J. A. \& HenTSCHKe, M. K. - 1980 - Common offset plane migration (COPMIG). Geophysical Prospecting, 28:859-871. [ Links ]

STOFFA, P. L., FOKKEMA, J. T., DE LUNA FREIRE, R. M. \& KESSINGER, W. P. - 1990 - Split-step Fourier migration. Geophysics, 56:410-421. [ Links ]

STOLT, R. H. - 1978 - Migration by Fourier transform. Geophysics, 43:23-48. [ Links ]

YILMAZ, O. - 1979 - Prestack partial migration: Ph. D Thesis, Stanford University. [ [ Links ]

YILMAZ, O. \& CLAERBOUT, J. F. - 1980 - Pre-stack partial migration. Geophysics, 45:1753-1779. [ Links ] 


\section{APÊNDICE A}

\section{Equação de Continuação Recursiva}

Este apêndice mostra como encontramos a Eq. (19), usando-se o método de fase estacionária. Para este fim, iremos escrever a Eq. (5) sem a soma em freqüência para os campos de onda em dois níveis de profundidade, a partir do campo medido na superfície $z=0$.

Considerando os campos de onda em dois níveis de subsuperfície, ou seja, $z_{1}$ e $z_{2}$, onde $z_{2}>z_{1}$, temos que

$P\left(\omega, k_{y}, h, z_{2}\right)=P\left(\omega, k_{y}, h, z=0\right) \int d k_{h} e^{j \int_{0}^{i_{1}} k_{s} d z^{\prime}} e^{-i k_{t} h}$

e

$P\left(\omega, k_{y}, h, z_{1}\right)=P\left(\omega, k_{y}, h, z=0\right) \int d k_{h} e^{i \int_{0}^{x_{1}} k_{y} d z^{*}} e^{-i k_{0} h}$

Dividindo-se a Eq. (A2) pela Eq. (A1), obtém-se

$P\left(\omega, k_{y}, h, z_{2}\right)=P\left(\omega, k_{y}, h, z_{1}\right) \frac{\int d k_{h} e^{i \int_{0}^{n_{2}} k_{z_{z}} d z^{\prime}} e^{-i k_{h} h}}{\int d h_{h} e^{i \int_{0}^{z_{1}} k_{z^{\prime}} d z^{\prime}} e^{-i k_{h} h}}$

Definindo a fase como sendo:

$\phi\left(k_{h}\right)=\int_{0}^{z} k_{z} \cdot d z^{\prime}-k_{h} h$.

As integrais que aparecem na Eq. (A.3) podem ser aproximadas assintoticamente (Born \& Wolf, 1975) por

$I(\omega, k y) \approx e^{i \phi\left(\hat{k}_{b}\right)} f\left(\hat{k}_{h}\right) e^{s i g n\left(\phi^{\prime \prime}\left(\hat{k}_{h}\right)\right) \frac{m}{4}}\left[\frac{2 \pi}{\mid \phi^{\prime \prime}\left(\hat{k}_{h}\right)}\right]^{1 / 2}$,

onde $\hat{k}_{h}$ é o ponto de fase estacionária. (Esta aproximação assume que a derivada segunda da fase é não nula.) Então, calculando-se cada integral que aparece na Eq. (A.3), obtemos

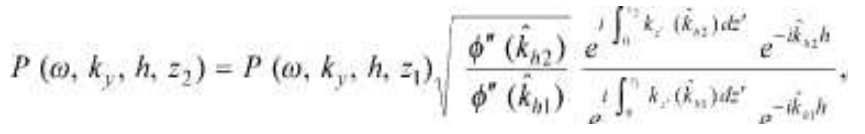

onde $\hat{k}_{h l}$ e $\hat{k}_{h 2}$ são as respectivas fases estacionárias.

A Eq. (A.6) permite a extrapolação do campo $P\left(w, k_{y}, h, z_{2}\right)$ a partir do campo $P\left(w, k_{y}, h, z_{1}\right)$ e é apresentada no texto principal como a Eq. (19).

Considerando-se o caso em que a seção a ser extrapolada seja de afastamento comum igual a zero, ou seja, $h=$ 0 . As fases $\hat{k}_{h 1} \hat{k}_{h 2}$ também são nulas, e, então, a Eq. (A.6) assume a seguinte forma:

$P\left(\omega, k_{y}, z_{2}\right)=P\left(\omega, k_{y}, z_{1}\right) e^{i \int_{z_{1}}^{z_{2}} k_{z} d z}$.

Considerando-se também que entre os níveis $z=z_{1}$ e $z_{2}=z+\mathrm{D} z$ a velocidade não varia, encontramos:

$P\left(\omega, k_{y}, z+\Delta z\right)=P\left(\omega, k_{y}, z\right) e^{i k_{z}(\omega, k} y_{y} \Delta z$ 
onde

$k_{z}=-\operatorname{sign}(\omega) \sqrt{\frac{4 \omega^{2}}{v(z)^{2}}-k_{y}^{2}}$.

A Eq. (A.9) é a equação que permite extrapolar o campo $P\left(w, k_{y}, z\right)$ de $z$ para $z+\mathrm{D} z$ através de uma simples mudança de fase. Portanto, a Eq. (A.7) se reduz, no caso de $h=0$ (seção de afastamento nulo), à migração "phase-shift" (Gazdag, 1978). Os métodos de migração baseados neste princípio são chamados de métodos de migração por mudança de fase.

\section{APÊNDICE B}

\section{Termo de Correção da Variação Lateral}

Para determinar o termo de correção do tipo "split-step" para dados ordenados em afastamento comum, começamos com a equação DSR dada por Claerbout (1985, pág. 180, Eq. 10):

$\frac{\partial P}{\hat{\sigma} z}=-i\left[\sqrt{\frac{\omega^{2}}{v^{2}(g)}-\frac{\hat{\partial}^{2}}{\partial g^{2}}}+\sqrt{\frac{\omega^{2}}{v^{2}(s)}-\frac{\hat{\partial}^{2}}{\partial s^{2}}}\right] P=i A P$,

onde $v(g)$ e $v(s)$ são as velocidades na fonte e no receptor, respectivamente, e $P=(P(w, x, z)$. Esta equação é conhecida como equação DSR no domínio fonte-receptor e permite a incorporação de variação lateral de velocidade.

Seguindo Ristow \& Ruhl (1994), iremos calcular a diferença entre os seguintes operadores

$d=\left(\sqrt{\frac{\omega^{2}}{v^{2}(g)}-\frac{\partial^{2}}{\partial g^{2}}}+\sqrt{\frac{\omega^{2}}{v^{2}(s)}-\frac{\hat{c}^{2}}{\partial s^{2}}}\right)-\left(\sqrt{\frac{\omega^{2}}{c^{2}}-\frac{\partial^{2}}{\partial g^{2}}}+\sqrt{\frac{\omega^{2}}{c^{2}}-\frac{\partial^{2}}{\partial s^{2}}}\right)$.

Expandindo em série de Taylor cada raiz quadrada e considerando apenas os termos de primeiro ordem, temos:

$$
\begin{aligned}
d & \approx\left(\frac{\omega}{v(g)}+\frac{\omega}{v(s)}-\frac{2 \omega}{c}\right)+\frac{\omega}{2 v(g)}\left(\frac{c}{v(g)}-1\right) \frac{v^{2}(g)}{\omega^{2}} \frac{\partial^{2}}{\partial g^{2}} \\
& +\frac{\omega}{2 v(s)}\left(\frac{c}{v(s)}-1\right) \frac{v^{2}(s)}{\omega^{2}} \frac{\partial^{2}}{\partial s^{2}}
\end{aligned}
$$

Combinando as Eq. (B2) e Eq. (B3), obtemos

$$
\begin{aligned}
& \sqrt{\frac{\theta^{2}}{v^{2}(g)}-\frac{\hat{\partial}^{2}}{\partial g^{2}}}+\sqrt{\frac{\omega^{2}}{v^{2}(s)}-\frac{\partial^{2}}{\partial s^{2}}}=\underbrace{\sqrt{\frac{\omega^{2}}{c^{2}}-\frac{\partial^{2}}{\partial g^{2}}}+\sqrt{\frac{\omega^{2}}{c^{2}}-\frac{\partial^{2}}{\partial s^{2}}}}_{\Lambda_{1}} \\
& +\underbrace{\left(\frac{\omega}{v(g)}+\frac{w}{v(s)}-\frac{200}{c}\right)}_{\text {A }} \\
& +\underbrace{\frac{\omega}{2 v(g)}\left(\frac{c}{v(g)}-1\right) \frac{v^{2}(g)}{\theta^{2}} \frac{\partial^{2}}{\partial g^{2}}+\frac{\omega}{2 v(s)}\left(\frac{c}{v(s)}-1\right) \frac{v^{2}(s)}{\omega^{2}} \frac{\hat{\sigma}^{2}}{\partial s^{2}}}_{\Lambda_{5}},
\end{aligned}
$$

onde $c$ é a velocidade constante de referência.

De forma mais simples, podemos escrever a Eq. (B.4) como

$A \approx A_{1}+A_{2}+A_{3}$

Desta forma, o operador exato, $A$, é separado em três operadores. O Operador $A_{1}$ é um operador do tipo "phase shift" a ser aplicado no domínio w $3 / 4 k_{y}$. O operador $A_{2}$ é um termo de correção de primeira ordem e reduz-se, no caso de $h=0 \frac{3}{4}$ seção de afastamento nulo, ao termo de Stoffa et al. (1990). O operador $A_{3}$ é um operador de segunda ordem.

A continuação para baixo pode ser realizada em duas etapas: na primeira fase o operador "phase-shift" é aplicado no domínio w $3 / 4 k_{y}$, e na segunda etapa do processo o operador $A_{2}$ ("split-step") é aplicado no domínio w $3 / 4$ y. A saída de cada operador é a entrada para o próximo operador. Este processo de continuação entre os níveis $z$ e $z+D z$ é realizado através de um processo de continuação em cascata da seguinte forma:

$P(z+\Delta z)=P(z) e^{-i \Delta \Delta z}=P(z) e^{-i A_{1} \Delta z} e^{-i A_{2} \Delta z}$

ou ainda, 
$P_{1}\left(\omega, k_{y}, h, z+\Delta z\right)=P\left(\omega, k_{y}, h, z\right) e^{-i A_{1} \Delta z}$

$P(\omega, y, h, z+\Delta z)=P_{1}(\omega, y, h, z) e^{-i A_{j} \Delta z}$

onde $P_{1}$ é um resultado intermerdiário.

Portanto, o termo de correção de primeira ordem a ser usado neste trabalho, visando a corrigir as variações laterais durante o processo de migração de dados de afastamento comum, é dado pelo operador $A_{2}$, como apresentado pela Eq. (20) do texto principal.

\section{SPLIT-STEP MIGRATION OF CONSTANT OFFSET DATA}

Pre-stack migration in frequency domain is based on downward continuation of both shots and receivers. The imaging condition requires selecting the image at zero time and zero offset. Pre-stack migration not only moves dipping events but also focuses the data to zero offset. Migration based on this double downward-continuation concept inherently focuses energy to zero offset and zero time, corresponding to extrapolating both shots and receivers to a coincident subsurface location. This type of migration is both fast and accurate, but is fundamentally limited to constant velocity. Pre-stack migration can also be formulated in midpoint-offset space and extended to variable velocity with depth. The extended pre-stack migration to depth dependent velocity, can be used to image media with lateral variation using a split-step correction. In the prestack frequency domain migration the data recorded at the surface $p(t, y, h, z=0)$ is transformed by a 3-D Fourier transform to $\left(w, k_{y}, k_{h}\right)$ domain and used to obtain the migrated image $p_{m}(t=0, y, h=0, z)$. In this work we are presenting a new method of pre-stack migration of seismic data in commom offset domain on media with lateral e vertical velocity variation. In our method each section of constant offset transformed to $\left(w, k_{y}, h\right)$ domain is migrated separately and the integration along the offset wavenumber is computed by the stationary phase method. The downward-continuation is done recursivelly in two steps. Using this procedure it was possible to extend the method to include vertically and laterally variable velocity. In the first one the wavefield is downward continued in depth in the $(\mathrm{w}, \mathrm{ky})$ domain, using a reference velocity. Then a split-step correction is applied in the extrapolated wave-field in the $\left(\mathrm{w}^{3 / 4} \mathrm{y}\right)$ domain. This correction is used to compensate for lateral velocity variations. We used this king of correction because it has been used and has shown goods results even when the velocity field presents a strong lateral variation. The split-step migration of constant offset data is very fast and tests demonstrated that this method offers good results when applied on synthetic data with vertical velocity variation, however it has limited efficiency on data with large offset and strong lateral variation.

All the contents of this journal, except where otherwise noted, is licensed under a Creative Commons Attribution License

SBGf

Av. Rio Branco, 156, sala 2510

20043-900 Rio de Janeiro RJ - Brazil

Tel. / Fax: (55 21) 2533-0064

etMail

sbgf@sbgf.org.br 